\title{
Suraksha Women Safety Device and Application
}

\author{
Reshma Hebbar ${ }^{1}$, Anisha A ${ }^{2}$, Balkis Hashiya ${ }^{3}$, Chaithra L ${ }^{4}$, Famiya Kauser ${ }^{5}$ \\ Assistant Prof, Dept of Computer Science, Shri Madhwa Vadiraja Institute of Technology and Management, Bantakal ${ }^{1}$ \\ Shri Madhwa Vadiraja Institute of Technology and Management, Bantakal ${ }^{2,3,4,5}$
}

\begin{abstract}
India which seeks itself as a promising super power and an economic hub, is still trapped in the clutches of various patriarchal evils like molestations, dowry, crime against women, worst among all is Rape. The atrocities against the women can be now brought to an end with the help of a device called Suraksha. This paper explains the basic idea underlying suraksha which is to flash a warning giving an instant location of the distressed victim to the police so that the incident could be prevented and the culprit apprehended. This would help reduce crime against women. This paper also summarizes other significant works in this field and hence forth discussed Suraksha device in a greater detail.
\end{abstract}

Keywords: Women, Security, Emergency, Android application, GSM, GPS.

\section{INTRODUCTION}

The device, named as "Suraksha" is a security system specially designed for women in distress. It is a simple and easy to carry device with magnanimous functionality. The basic approach is to intimidate instant location and a distress message to the cops and registered number, so that unfortunate incidents would be averted and to provide real time evidence for swift action against the perpetrators of crime against women. Currently the work is under process to miniaturize it so that it could be embedded in jewelleries, mobile phones etc in order to make it a versatile instrument for masses. It can play a major role in the upcoming projects such as CCTNS (crime and criminal tracking network and system) in which all the police records all over India are digitized and all the police station throughout the country will be integrated.

A smart phone has many applications which is useful to people in which our "Suraksha" will become one of those. It is a personal safety product designed to keep you and your friends safe 24/7. It is packed with features for both everyday safety and real emergencies, making it an ultimate tool for all. This user-friendly application can be accessed by anyone who has installed it in their smart phones as well as who has our device. The basic approach (single click) is to intimidate the instant location and a distress message to the cops and the preset numbers, so that unfortunate incident can be averted and to provide real time evidence for the action against the perpetrators of crime against women.

\section{RELATED WORK}

A. Amrita Personal Safety System (APSS), a new technology to protect women from potential rapists and sexual offenders. APSS is an inconspicuous, wearable and easy- 788 Nishant Bhardwaj and Nitish Aggarwal to operate electronic device that will help women in establishing communication with family and police at the first sign of trouble. The device will remain invisible to the criminals and yet can easily be triggered by the user with multiple options, to ensure steady and secure communication.

B. "VithU" is an emergency App that, at the click of the power button of your Smartphone 2 times consecutively begins sending out alert messages every 2 minutes to your contacts that you feed into the app as the designated receivers or guardians.

C. Jivi 2010 is a feature of Jivi mobile with a fully dedicated SOS button aimed at women. In case of any emergency or unfortunate times, user needs to longpress the SOS button and the phone starts calling 5 pre-stored numbers one after the other. In case any of the numbers is busy or does not take the call, a SMS is sent to the number. After this, the phone automatically dials other numbers on the pre-defined list - thereby ensuring immediate help.

\section{METHODOLOGY}

\section{A. Hardware Device}

Figure 1 shows the methodology of the hardware device. The device can be initiated by just pressing the emergency button once. This device starts functioning and sends current location along with an emergency message to police and pre-stored contacts seeking help through a GSM module. The figure 4 shows the outlook of the hardware device. The device makes a call to pre-stored contacts when the emergency button is double clicked. When the emergency button is pressed for a long duration it activates a call to the pre-stored contacts, police and sends a emergency message with an 


\section{International Journal of Innovative Research in Electrical, Electronics, Instrumentation and Control Engineering}

\section{ISO 3297:2007 Certified}

Vol. 5, Issue 5, May 2017

instant location. The location information is collected using GPS (NEO-6M-0-001 u-blox AG) and call is made from GSM modem. This GSM modem (SIM 900) just acts like a mobile phone with its unique mobile number and can accept any GSM network operator SIM card. The main advantage of using this modem is that we can communicate and develop embedded applications using its RS232 port. It can be used to make/receive voice calls or to send and receive SMS. In order to help our privacy the radio frequency receiver, that is used to detect hidden camera in the surrounding area. If any hidden camera is there then it will alert the user by glowing the LED's. It detects camera when the RF signal is interrupted. We can also synchronize our device with our mobile (through Bluetooth HC05), to find the location of our mobile in case if it is lost. The location of the mobile is sent to the pre-stored numbers when track your mobile button is clicked in hardware.

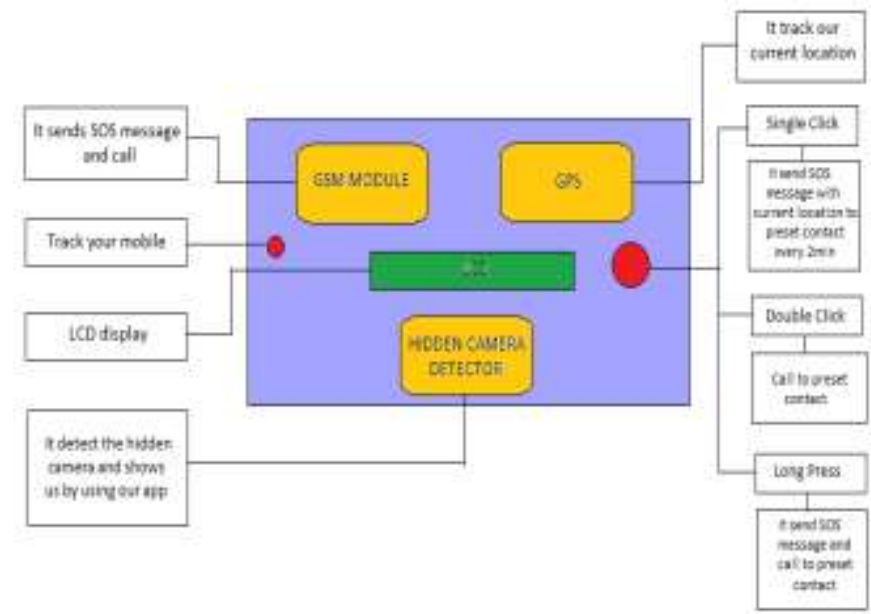

Figure1. Structure of the Device.

\section{B. Android Application}

Figure 2 shows the general methodology of the android application. When you click on the application, there is a thread and then it leads title main page, which consists of four buttons. These buttons guide the user during emergencies, depending upon the situation the user can choose the button. When you click on the following buttons the following pages like SOS, Audio Record, Video Record and Detect camera pages will be opened.

The user can give the input to the application in two ways, either manually or by pressing the volume button. First the user initiates the application by going inside it and clicking on the application icon. Then the name of the application is displayed after a thread of 2 seconds is rendered. Then after this process terminates process where the user can interact with the application is initiated. This page allows the user to interact with the application. When user clicks on each icon it takes the user to the respective page. The four different buttons used in our application are SOS, Audio Record, Video Record and Detect camera. The application gets open automatically when the user clicks on the emergency button (Volume button). This will avoid the user to spend time in searching the application and enables the user to take appropriate action as soon as possible. Figure 3 represents the general methodology of the device and the application.

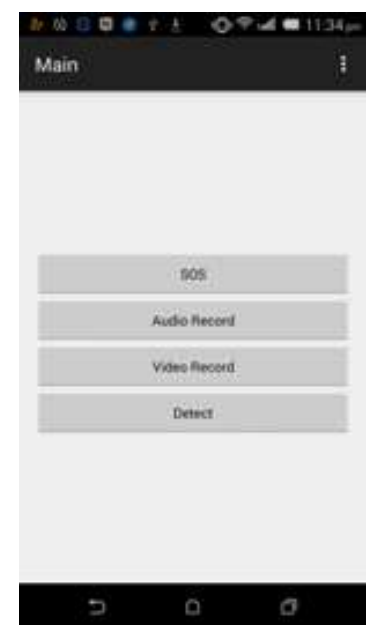

Figure 2 Structure of Android Application. 


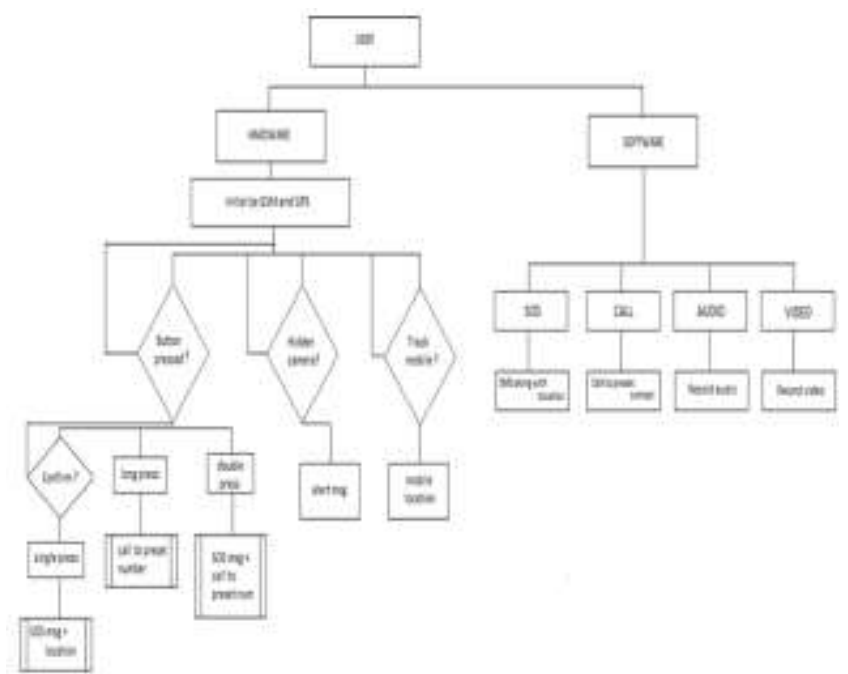

Figure 3 General methodology of the device and the application.

\section{INTERNAL WORKING}

\section{A. SOS}

On first click it activates the system, which sends the message including the user location to the registered contacts. At the receiver, just by clicking on the location ink provided in the message it can show the location on the Google map.

B. Hidden Camera

Hidden camera detector picks up electromagnetic signals that are broadcasted using radio frequency receiver from electronic device such as spy camera. If it detects the spy camera, alert the user about the hidden camera by lighting up in the device.

C. Video Recorder

Video recorder starts recording whenever "Suraksha" app is activated and records the video for future investigation.

D. Audio Recorder

Audio recorder is in the software, which records the audio when device is activated and help police in investigation.

\section{PROPOSED SYSTEM}

Using the Arduino Uno which is a microcontroller board based on the ATmega328, the Suraksha safety device is connected with GSM for calling and sending messages, GPS for finding the location by giving latitude and longitude value, Bluetooth and RF detector for the purpose of detecting spy camera. The device uses 5V power supply for the processing.

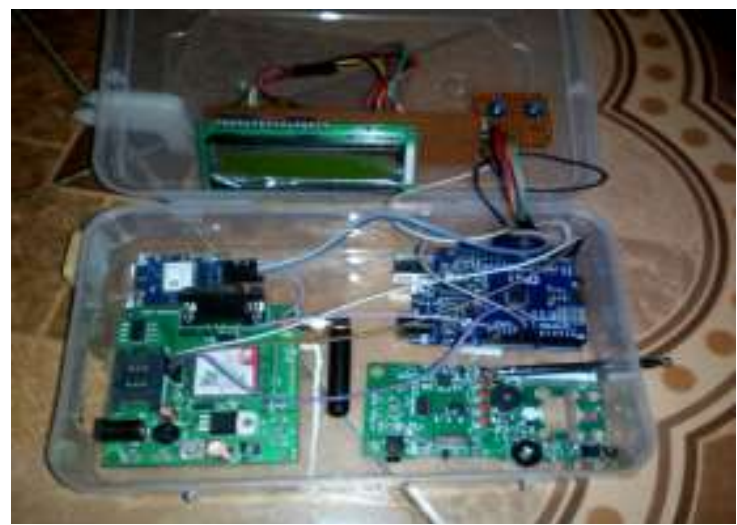

Figure 4 Complete Prototype.

Figure 4 represents the complete prototype of the device which can be miniature in the future. The Suraksha device has both hardware and software. She can use either hardware or software application or both. The hardware device is used to call and send the emergency message pre-stored contacts when the button is pre-stored. In case of emergency, it is 


\section{International Journal of Innovative Research in Electrical, Electronics, Instrumentation and Control Engineering}

\section{ISO 3297:2007 Certified}

Vol. 5, Issue 5, May 2017

also possible to seek help from the nearby police station using the hardware device. In addition, the spy cameras can also be detected using the device. The software application is used for the same purpose along with the option for recording audio and video for further investigation.

\section{MATERIALS REQUIRED}

\begin{tabular}{|l|l|l|}
\hline \multicolumn{2}{|c|}{ Hardware Specifications } & \multicolumn{2}{c|}{ Software Specifications } \\
\hline \multicolumn{1}{|c|}{ Hardware Requirements } & \multicolumn{1}{|c|}{ Hardware Requirements } & \multicolumn{1}{c|}{ Software Requirements } \\
\hline GPS Module (NEO-6M-0-001 u-blox AG) & Processor: Pentium IV & Platform: Windows 7,8.1 \\
$\begin{array}{l}\text { GSM (sim 900), Arduino Uno } \\
\text { microcontroller, Bluetooth (HC 05) }\end{array}$ & RAM: 512 Mb & Front End: Android Studio, Java \\
$\begin{array}{l}\text { LCD device, Hidden camera detector } \\
\text { Other components }\end{array}$ & & $\begin{array}{l}\text { JDK } \\
\text { Back End: MS SQL Server, } \\
\text { Android Phone }\end{array}$ \\
\hline
\end{tabular}

\section{RESULT}

Software

"Suraksha" application consists of four different options such as SOS, Audio record, Video record and Hidden camera detector. With the help of SOS we can send emergency message along with longitude and latitude to the pre-set contacts. Audio and video Recording can help in Investigation. Hidden camera detector can help in our privacy. An emergency Button is provided i.e. volume key. When emergency button is pressed, application gets activated and sends emergency message along with longitude and latitude is sent to the pre-set contacts.

\section{E. Hardware}

On first click, emergency message along with longitude and latitude is sent to the pre-set contacts. On double click; a call is connected to pre-set contacts. On long press, emergency message along with longitude and latitude is sent to the pre-set contacts and call is connected to pre-set contacts or to cops. It provides a tool to detect the spy camera placed at changing room, hotel etc., and it informs the user by glowing the LED light.

\section{CONCLUSION}

The main aim of this project is to make women feel safe and secure in our society. Implementing a device and real time application, can solve many problems (Being stalked, Unsafe neighbor, Domestic violence, robbery, sexual assault) to an extent. In some of the cases the system can provide useful evidences. Since the Application can do audio-video recording of incidences which can act as the evidences. Women's security is a critical and social issue in today's world. The crime against the women can be now brought to an end.

\section{REFERENCES}

[1] MAGESH KUMAR.S and RAJ KUMAR.M, "IPROB - EMERGENCY APPLICATION FOR WOMEN", Department of Computer science Sree Krishna College of Engineering Unai village Vellore (TN) India, ISSN 2250-3153 International Journal of Scientific and Research Publications, online at the link www.ijsrp.org, Volume 4, Issue 3, March 2014

[2] Dr. Sridhar Mandapati, SravyaPamidi and SriharithaAmbati, "A Mobile Based Women Safety Application (I Safe Apps)", Department of Computer Applications R.V.R \& J.C College of Engineering Guntur India, e-ISSN: 2278-0661, p-ISSN: 2278-8727, IOSR Journal of Computer Engg (IOSR-JCE) www.iosrjournals.org, Volume 17, Issue 1 (Version I), PP 29-34, Jan.-Feb. 2015.

[3] NishantBhardwaj and NitishAggarwal, "Design and Development of "Suraksha"-A Women Safety Device", Department of Electronics and Communication ITM UNIVERSITY Huda Sector 23-A Gurgaon Delhi India, ISSN 0974-2239 International Journal of Information \& Computation Technology online available at http://www.irphouse.com, Volume 4, pp. 787-792, November 2014.

[4] PoonamBhilare, AkshayMohite, DhanashriKamble, SwapnilMakode and RasikaKahane, "Women Employee Security System using GPS And GSM Based Vehicle Tracking", Department of Computer Engineering Vishwakarma IOT SavitribaiPhule Pune University India, E-ISSN:2349-7610 INTERNATIONAL JOURNAL FOR RESEARCH IN EMERGING SCIENCE AND TECHNOLOGY, Volume-2, ISSUE-1, JAN-2015.

[5] Chand D, Nayak S, Bhat KS, Parikh S. A mobile applicationfor Women's Safety: WoS App. 2015 IEEE Region 10 Conference TENCON; Macao. 2015 Nov 1-4. p. 1-5.

[6] SMART GIRLS SECURITY SYSTEM by Prof. BasavarajChougula, ArchanaNaik, Monika Monu, PriyaPatil and Priyanka Das, Volume 3,Issue 4, April 2014, International Journal of Application or Innovation in Engineering \& Management

[7] TumanPoddar, Ritesh C, NagarajaBharath-“USING WEARABLE TECHNOLOGY TO ANSWERWOMEN'S SAFETY”, International Journal of Science, Technology \& Management www.ijstm.comVolume No.04, Issue No. 05, May 2015

[8] Self defence system for women with location tracking and SMS alerting through GSM network-B.Vijaylashmi, Renuka.S, PoojaChennur, Sharangowda. Patil International Journal of Research in Engineering and Technology(IJRET) eISSN: 2319-1163 | pISSN: 2321-7308 Volume: 04 Special Issue: 05

[9] Ravi SekharYarrabothu,BramarambikaThota-“ABHAYA: AN ANDROID APP FOR THE SAFETYOF WOMEN” 